\title{
Cultivo do Feijoeiro em Solo de Baixa Fertilidade em Sucessão à Cultivares de Batata Submetidas a Diferentes Adubações
}

\author{
1Marcelo Bregagnoli; 2Keigo Minami; 3Ariana Vieira Silva; 4Raul Henrique Sartori \\ 1IFSULDEMINAS - campus Muzambinho, caixa postal 02, 37890-000, Muzambinho, MG, 035 - 3571-5051, \\ e-mail: mbrega@eafmuz.gov.br \\ 2ESALQ/USP, Departamento de Fitotecnia, Piracicaba, SP, e-mail: kminami@esalq.usp.br \\ 3IFSULDEMINAS - campus Muzambinho, caixa postal 02, 37890-000, Muzambinho, MG, 035 - 3571-5051, \\ e-mail: ariana@eafmuz.gov.br \\ 4IFSULDEMINAS - campus Muzambinho, caixa postal 02, 37890-000, Muzambinho, MG, 035 - 3571-5051, \\ e-mail: raul@eafmuz.gov.br
}

\section{RESUMO}

A utilização de adubos residuais da batateira na sucessão de culturas, especialmente para o feijão, por se tratar de uma planta de baixa exigência nutricional e um produto que constituí o hábito alimentar do brasileiro, mesmo sendo pouco estudada e compreendida pelos agricultores. Assim, objetivou-se com o presente estudo, avaliar o teor foliar e a produtividade do feijoeiro em sucessão a diferentes cultivares de batata, em solo de baixa fertilidade, sob diferentes adubações e a melhor interação na produção de batata, em massa seca total, e o feijoeiro. O experimento foi instalado em Latossolo Vermelho Distrófico, de textura franco-arenosa, município de Nova Resende, sul de Minas Gerais, no inverno de 2004 (batata) e verão 2004/2005 (feijoeiro). O delineamento estatístico foi de blocos ao acaso, com quatro repetições e esquema fatorial $3 \times 4$ envolvendo com três cultivares de batata (Atlantic, Asterix e Lady Rosetta) e quatro adubações no plantio (1, 2 e 4 t ha-1 de fertilizante formulado 4-14-8) e mais um tratamento testemunha, constituído por adubação recomendada com base na análise de solo (40 kg de $\mathrm{N}+420$ $\mathrm{kg} \mathrm{P} 2 \mathrm{O} 5+220 \mathrm{~kg}$ de K2O ha-1). Em sucessão, na safra das águas, nas mesmas parcelas anteriores, implantouse a cultura do feijoeiro, cultivar Pérola (grupo carioca). A concentração de fertilizantes anteriormente utilizadas para a cultura da batata não afetou a germinação do feijoeiro. Os resultados da análise foliar do feijoeiro, aos 55 dias após semeadura, indicaram maiores valores acumulados de $\mathrm{N}$ e $\mathrm{P}$ na dose de $4 \mathrm{t}$ ha-1 da formulação NPK, mas com efeito depressivo sobre o teor de Mg. Nas parcelas posteriores a cultivar de batata Lady Rosetta, o teor de $\mathrm{Ca}$ foi reduzido. Os teores de $\mathrm{Cu}$ foram elevados, sobretudo nos tratamentos cultivados anteriormente com 'Atlantic' e no tratamento com 4 t 4-14-8 ha-1. A adubação de acordo com a análise de solo resultou no maior teor foliar de B no feijoeiro, $60 \%$ superiores aos demais tratamentos de adubações. A adubação de acordo com a análise de solo resultou na maior produtividade no feijoeiro em cultivo sucessivo. A adubação com 2 t $4-14-8$ ha-1 resultou na melhor interação para a produção de massa seca total da batata e produtividade de grãos no feijoeiro.

Palavras-chave: Solanum tuberosum L.; Phaseolus vulgaris L.; sucessão de culturas.

\section{Crops field of Bean in Soil of Low Fertility in Succession to Potato Cultivars Under Different Fertilization}

\section{ABSTRACT}

The use of residual fertilizer in the potato crop succession, especially for beans, especially because it is a plant of low nutritional requirements and a product that is the one of the main Brazilian food and eating habits, even though it is still a crop little studied and understood by farmers. Thus, the aim of the present study was to evaluate the content and productivity of bean leaf in succession to different potato cultivars in low fertility soil under different fertilization and better interaction in potato production, total dry mass, and the bean. The experiment was installed in a typic dystrophic, sandy loam texture, in the city of Nova Resende, south of Minas Gerais, during the winter of 2004 (potato) and summer 2004/2005 (bean). The statistical design was randomized blocks with four replications and $3 \mathrm{x}$ 4 factorial design involving three potato cultivars (Atlantic, Asterix and Lady Rosetta) and four fertilization at planting (1, 2 and $4 \mathrm{t}$ ha-1 fertilizer formulated 4-14-8), plus a control treatment, consisting of fertilizer recommended on the basis of analysis of soil (40 kg N $+420 \mathrm{~kg} \mathrm{P} 2 \mathrm{O} 5+220 \mathrm{~kg} \mathrm{~K} 2 \mathrm{O}$ ha-1). In succession, the harvest of the waters, in the same previous installments, it was implanted black bean cultivar Perola (Group Carioca). The fertilizer concentration previously used for cultivation of potatoes did not affect the germination of bean. The results of the analysis of bean leaf, 55 days after sowing, indicated higher values of $\mathrm{N}$ and $\mathrm{P}$ accumulated in a dose of $4 \mathrm{t}$ ha- 1 NPK, but 
depressing effect on the $\mathrm{Mg}$ content. In the plots after the potato cultivar Lady Rosetta, the Ca content was reduced. The levels of Cu were high, especially in the earlier treatments grown with 'Atlantic' and treatment with 4 t ha-1 4-14-8. The fertilizer according to the soil analysis resulted in higher foliar $\mathrm{B}$ in the bean, $60 \%$ higher than other fertilization treatments. The fertilizer according to soil analysis resulted in higher productivity in the bean crop in succession. A 4-14-8 fertilizer with $2 \mathrm{t}$ ha-1 resulted in better interaction for the production of total dry mass of potato and grain yield in common bean.

Key words: Solanum tuberosum L.; Phaseolus vulgaris L.; sequential crops.

\section{INTRODUÇÃo}

De cultivo complexo, ciclo curto e alta produção por área, a batateira é exigente em nutrientes, com a adubação influenciando na quantidade e qualidade dos tubérculos (Filgueira, 2000). A extração de nutrientes pela cultura é variável em função de diferentes cultivares, condições edafoclimáticas, tratos culturais, tubérculossemente, adubos utilizados e da quantidade de nutrientes absorvidos e exportados pelos tubérculos (Fontes, 1997).

O excesso da adubação pode tornar a atividade onerosa e afetar a qualidade dos tubérculos. A batateira ocupa a primeira posição no consumo de fertilizantes, entre as culturas mais cultivadas no Brasil, em média de 2,3 a 2,8 tha-1 de fertilizantes no plantio (Neves et al., 2003), chegando a $6 \mathrm{t}$ ha-1 (Ribeiro, 1999). Analisando 1000 experimentos de diferentes países, verificou-se que as maiores produções de batata foram atingidas quando se empregou de 200 a $300 \mathrm{~kg}$ de N, 100 a $200 \mathrm{~kg}$ de P2O5 e 100 kg de K2O ha-1 (Perrenoud, 1993).

A aquisição de batata-semente, defensivos e fertilizantes na bataticultura, representa de 65 a $85 \%$ do custo final (Camargo Filho, 2001). Os impactos ambientais advindos desta prática devem ser considerados, como a lixiviação de $\mathrm{K}$ e $\mathrm{N}$, contaminando o lençol freático (Bregagnoli, 2006).

Estratégias são necessárias para aperfeiçoar a aplicação de fertilizantes (eficiência econômica), com grandes quantidades de nutrientes empregadas para a batateira, superiores às necessidades fisiológicas, com baixo aproveitamento pela planta (Fontes, 1997). Teores foliares de nutrientes servem como importante indicativo da eficiência da absorção dos nutrientes contidos no solo, assim como a sucessão de culturas são estratégias verificando-se o sistema como um todo, no entanto, com pouco embasamento científico.

Inúmeras são as tentativas de aproveitamento destes nutrientes no solo remanescentes da cultura da batata, como na cana-de-açúcar (Goviden, 1990; Iman et al., 1990), no milho (Batugal et al., 1990; Silva et al., 2000; Kikuti et al., 2002a) e, especialmente para o feijoeiro (Silva Filho, 1986, Kikuti et al., 2002b), cultura de fácil cultivo, de elevada demanda interna e de excelente valor de mercado, aumentando a eficiência do sistema com maiores períodos de rotação e menor uso da solanácea, resultando em vantagens agronômicas e ambientais (Stark \& Porter, 2005).

No sul de Minas Gerais, a utilização de feijão em sucessão a batata é uma atividade bastante difundida, onde se tem estudado diversas interações entre espécies vegetais, cultivares, estratégias de adubação e safras, etc.(Kikuti et al., 2002b). Busca-se a maior utilização e eficiência do uso solo, com rentabilidade das culturas, com maior retorno financeiro.

Objetivou-se, com o presente estudo, avaliar o teor foliar e a produtividade do feijoeiro (cultivar Pérola) em sucessão a diferentes cultivares de batata, em solo de baixa fertilidade, sob diferentes adubações e a melhor interação na produção de batata, em massa seca total, e o feijoeiro.

\section{MATERIAL E MÉTODOS}

O experimento foi conduzido no período de 18 de junho a 07 de outubro de 2004 (batata) e de 20 de outubro de 2004 a 15 de fevereiro de 2005 (feijão), na Fazenda Goiabeiras, município de Nova Resende, sul de Minas Gerais, $21^{\circ} 7^{\prime}$ '14" latitude (S) e 46 26' $0^{\prime \prime}$ longitude (W) a $1210 \mathrm{~m}$ de altitude.

Durante o cultivo da batata, a temperatura média foi de $17,3^{\circ} \mathrm{C}$, a precipitação pluvial foi $93,6 \mathrm{~mm}$, suplantados com irrigação. Durante o ciclo do feijoeiro, a temperatura média foi de $19,6^{\circ} \mathrm{C}$ e a precipitação 978 $\mathrm{mm}$ no ciclo. O solo da área experimental é Latossolo Vermelho Distrófico, de textura franco-arenosa e suas características químicas apresentadas na Tabela 1.

Tabela 1 - Resultado análise de solo antes da instalação cãs culturas da batata e do feijoeiro. Nova Resende (MG), 2004

\begin{tabular}{|c|c|c|c|c|c|c|c|c|c|c|c|c|c|c|c|c|}
\hline $\mathrm{pH}$ & M.O. & P2O5 & K2O & $\mathrm{Ca}$ & $\mathrm{Mg}$ & $\mathrm{Al}$ & $\mathrm{H}+\mathrm{Al}$ & SB & $\mathrm{T}$ & $\mathbf{V}$ & $\mathrm{Zn}$ & $\mathrm{Fe}$ & Mn & $\mathrm{Cu}$ & $B$ & $S$ \\
\hline $\mathrm{H} 2 \mathrm{O}$ & $\begin{array}{l}\text { dag } \\
\mathrm{kg}-1\end{array}$ & $\begin{array}{c}\mathrm{mg} \\
\mathrm{dm}-3\end{array}$ & $\begin{array}{c}\text { cmolc } \\
\mathrm{dm}-3\end{array}$ & $\%$ & $\begin{array}{c}\mathrm{mg} \\
\mathrm{dm}-3\end{array}$ & & & & & & & & & & & \\
\hline 6,12 & 2,74 & 4,7 & 127 & 1,8 & 0,7 & 0,03 & 2,5 & 2,8 & 5,32 & 53 & 3,16 & 107 & 15,2 & 1,48 & 0,7 & 8,4 \\
\hline
\end{tabular}


O cultivo da batata ocorreu em delineamento experimental de blocos ao acaso, com quatro repetições e esquema fatorial de $3 \times 4$ envolvendo três cultivares de batata (Atlantic, Asterix e Lady Rosetta) e quatro adubações no plantio da solanácea (1, 2 e 4 tha-1 do formulado 4-14-8), mais adubação recomendada (Fontes, 1997), com base na análise de solo (40 kg de $N+420$ $\mathrm{kg} \mathrm{P} 2 \mathrm{O} 5+220 \mathrm{~kg}$ de $\mathrm{K} 2 \mathrm{O}$ ha-1 utilizando como fontes sulfato de amônio, superfosfato simples e cloreto de potássio). Em cobertura para todos os tratamentos foram utilizados $150 \mathrm{~kg}$ ha-1de sulfato de amônio (sulfato de amônio). A área da parcela experimental para a batata foi de $7,2 \mathrm{~m} 2$, com tubérculos em quatro linhas de plantio, espaçada 0,8 metro entre linhas e 0,3 metro entre tubérculos, com a densidade de 41.667 tubérculos ha-1.

Em sucessão instalou-se a cultura do feijoeiro, cultivar Pérola (grupo carioca), utilizando as mesmas parcelas experimentais da batateira com $7,2 \mathrm{~m} 2$. As parcelas foram constituídas por 3 linhas de 5 metros, espaçadas $0,5 \mathrm{~m}$ entre si e 12 sementes por metro, utilizando os adubos residuais da cultura da batata. As sementes utilizadas para plantio apresentavam $92 \%$ de germinação, $0,5 \%$ de impurezas e estande final de 220.000 plantas ha-1.

A leguminosa recebeu adubação de cobertura com $30 \mathrm{~kg}$ de $\mathrm{N}$ e $10 \mathrm{~kg}$ de $\mathrm{K} 2 \mathrm{O}$ ha-1 (fonte formulado 30-00-10) e aplicação foliar em pré-florada (40 dias após semeio - DAS) com fungicida (metalaxyl), inseticida (malathion) e fertilizante solúvel (10-10-10 + Mg, Zn, Cu, $\mathrm{Mn}$ e Mo).

Na batata, avaliou-se a produtividade de tubérculos e o teor de massa seca total (MST). No feijoeiro, avaliou-se o número de plantas emergidas (15 DAS); o teor foliar de nutrientes foliares (55 DAS) e a produtividade de grãos (colheita).

O teor de nutrientes foi determinado pelo terceiro trifólio de plantas coletados ao acaso, utilizando digestão nitro-perclórica para os elementos, exceto para $\mathrm{N} \mathrm{e} \mathrm{B}$ obtidos, via digestão catalítica e seca, respectivamente (Sarruge \& Haag, 1974). Os métodos empregados para determinação foram: $\mathrm{K}$ (espectrofotometria de chama), $\mathrm{P}$ (colorometria do metavanadato), $\mathrm{S}$ (turbidimetria do sulfato de Bário), $\mathrm{Ca}, \mathrm{Mg}, \mathrm{Zn}, \mathrm{Cu}, \mathrm{Mn}$ e Fe (espectrometria de absorção atômica), B (colorometria da azometina-H) e N (semi-Kjeldahl), (Malavolta et al., 1997). A produtividade do feijoeiro foi determinada a partir da colheita das vagens no estádio de maturação, secas em terreiro e pesado os grãos.

Realizou-se a análise estatística, a distribuição normal e o desvio padrão dos resultados, a homogeneidade das variâncias e o Teste de Tukey para comparação das médias, a $5 \%$ de probabilidade, utilizando o software estatístico SAS.

\section{RESULTADOS E DISCUSSÃO}

\section{Germinação do feijoeiro}

Não existiram diferenças significativas entre os tratamentos quanto à emergência das plantas do feijoeiro $(P \geq 0,05)$, demonstrando que a quantidade de fertilizantes utilizados para a batata, não influiu sobre a germinação do feijão em sucessão, não apresentando higroscopicidade à semente no período chuvoso, no qual foi instalado o experimento.

\section{Teor foliar de nutrientes}

O teor dos nutrientes foliares do feijoeiro aos 55 DAS apresentou diferenças significativas $(P<0,05)$ entre as parcelas nos tratamentos: adubações e cultivares de batata cultivada anteriormente.

O teor de $\mathrm{N}$ apresentou variação de 4,85 a $5,32 \%$ entre os tratamentos, com valores concordantes com Malavolta et al. (1997), que relatam como ideal para o feijoeiro de 3 a $5 \%$. Os maiores teores de $\mathrm{N}$ foram observados na dose máxima de fertilizante (4 t 4-14-8 ha-1) em todas cultivares de batata anteriormente cultivadas, similar ao observado por Silva et al. (2000) para a mesma dose do adubo residual na cultura do feijão.

Similar ao ocorrido com $\mathrm{N}$, o teor de $\mathrm{P}$ foi de 0,36\% na maior adubação anterior (4 t 4-14-8 ha-1), $16,7 \%$ superior as demais adubações residuais. Malavolta et al. (1997) definem como valores ideais de P aqueles entre 0,2 e $0,3 \%$, valores inferiores aos obtidos neste experimento, apontando que o uso de adubação residual da batateira para o feijoeiro, atende à necessidade da planta em P.

Com relação ao teor de $\mathrm{K}$, a variação foi de 2,09 a $2,58 \%$, dentro da faixa recomendada de 2,00 a 2,50\% (Malavolta et al., 1997), sem diferenças significativas entre os tratamentos (adubação $x$ cultivares batata). Provavelmente, isso decorre a baixa capacidade residual do K, altamente lixiviável, sobretudo em solos de textura arenosa (Fassbender \& Bornemiza, 1987).

$\mathrm{Na}$ análise foliar do feijoeiro nas parcelas anteriormente cultivadas com 'Lady Rosetta' (em todas as adubações), houve um decréscimo de $8 \%$ no teor de $\mathrm{Ca}$, quando comparada as demais cultivares de batata. No tratamento com 2 t 4-14-8 ha-1, observaou o maior teor de Ca foliar para o feijoeiro (média de 1,92\%), 12,5\% superior às demais adubações. O teor recomendado para o feijoeiro é de 1,50 a 2,00\% (Malavolta et al.,1997).

Os teores foliares de $\mathrm{Mg}$ e $\mathrm{S}$ médios observados foram de 0,40 e $0,38 \%$, respectivamente, menores que os indicados por Malavolta et al. (1997) que são de 0,40 a $0,70 \%(\mathrm{Mg})$ e 0,50 a $1,00 \%(\mathrm{~S})$. O baixo teor de $\mathrm{Mg}$ foliar se deve provavelmente, a elevada adubação potássica empregada na batata (efeito antagônico $\mathrm{K} \mathrm{x}$ $\mathrm{Mg}$ ), que na menor dosagem da formulação 4-14-8 (2 t) foi de $80 \mathrm{~kg}$ e, na maior (4 t), $320 \mathrm{~kg}$ de $\mathrm{K} 2 \mathrm{O}$ ha-1 plantio, 
o que pode ter exercido forte influência sobre a absorção de $\mathrm{Mg}$ pelo feijoeiro. A adubação de acordo com a análise de solo utilizada para a batateira, residual ao feijoeiro, resultou no menor teor foliar de $S$ com $0,34 \%$ aos 55 DAS, mesmo com a presença de sulfatos na sua composição.

$\mathrm{Na}$ análise foliar para os micronutrientes, o teor de Fe foi elevado (mas dentro do recomendado), sobretudo na adubação com 4 t 4-14-8 ha-1, com 360 mg kg-1 nas folhas do feijoeiro, com as demais adubações apresentando média de $282 \mathrm{mg} \mathrm{kg}-1$. Entre as cultivares de batata anteriormente cultivada, 'Lady Rosetta' apresentou $15 \%$ menos. O teor foliar de Fe para o feijoeiro é de 100 a 400 mg kg-1 (Malavolta et al.,1997).

O teor foliar de $\mathrm{Zn}$ para o feijoeiro nas parcelas anteriormente cultivadas com a cultivar Asterix apresentou $15 \%$ mais $\mathrm{Zn}(82,8 \mathrm{mg} \mathrm{kg}-1)$, dentro da faixa ideal para o feijoeiro que é de 20 a $100 \mathrm{mg} \mathrm{kg}-1$ (Malavolta et al., 1997).

O menor teor de Mn foi observado onde, anteriormente, havia sido utilizada a cultivar Lady Rosetta (16\% menor) com 217,3 mg kg-1, mas dentro do ideal, que varia de 30 a $300 \mathrm{mg} \mathrm{kg-1}$ (Malavolta et al.,1997).

O cultivo sucessivo do feijoeiro nas parcelas anteriormente cultivadas com 'Atlantic', resultou em altos teores de Cu foliar, com 45,5 mg kg-1, $23 \%$ superior as demais cultivares, sendo que para este elemento, a adubação de maior incremento no teor foliar de $\mathrm{Cu}$, foi aquela feita na dose de $4 \mathrm{t}$ 4-14-8 ha-1, elevando em $55 \%$ o teor foliar do feijoeiro $(57,0 \mathrm{mg} \mathrm{kg}-1)$. O teor de $\mathrm{Cu}$ observado neste experimento para todos os tratamentos e suas interações (adubação x cultivares de batata), são superiores ao recomendado por Malavolta et al. (1997) que varia de 10 a $20 \mathrm{mg} \mathrm{kg}-1$, proveniente do elevado emprego de fungicidas a base de íons metálicos como o Cu, utilizados para a batateira, uma vez que na análise foliar e de tubérculos na colheita da batata, também apresentaram elevado valor para este elemento.

Em relação ao teor foliar de $B$, este micronutriente apresentou elevada concentração no resíduo da batateira, quando se empregou a adubação de acordo com a análise de solo, $60 \%$ superior as demais adubações (107 mg kg-1) valor acima do recomendado por Malavolta et al. (1997) que é de 30 a $60 \mathrm{mg} \mathrm{kg-1.} \mathrm{Cuidados}$ devem ser tomados para o correto balanceamento entre nutrientes, pois, o excesso de B pode interferir na dinâmica de absorção e translocação do Zn e N na batateira (Westermann, 2005).

\section{Produtividade do feijoeiro $x$ produção de MS da batata}

As cultivares de batata anteriormente cultivada, apresentaram diferentes acúmulos de massa seca total (MST) nos tubérculos $(P \leq 0,01)$. Esta medida torna-se importante, uma vez que o maior acúmulo de MS pelos tubérculos, teoricamente, pode resultar em menor disponibilidade de nutrientes às culturas sucessivas, uma vez que estes são componentes importantes da MS, especialmente na batateira. 'Atlantic' foi a cultivar que mais acumulou MS nos tubérculos colhidos, totalizando $3063 \mathrm{~kg}$ ha-1, superior a 'Asterix' que apresentou $2527 \mathrm{~kg}$ de MS ha-1. Com menor acúmulo de MS, 'Lady Rosetta' apresentou 2216 kg ha-1 (Figura 1).

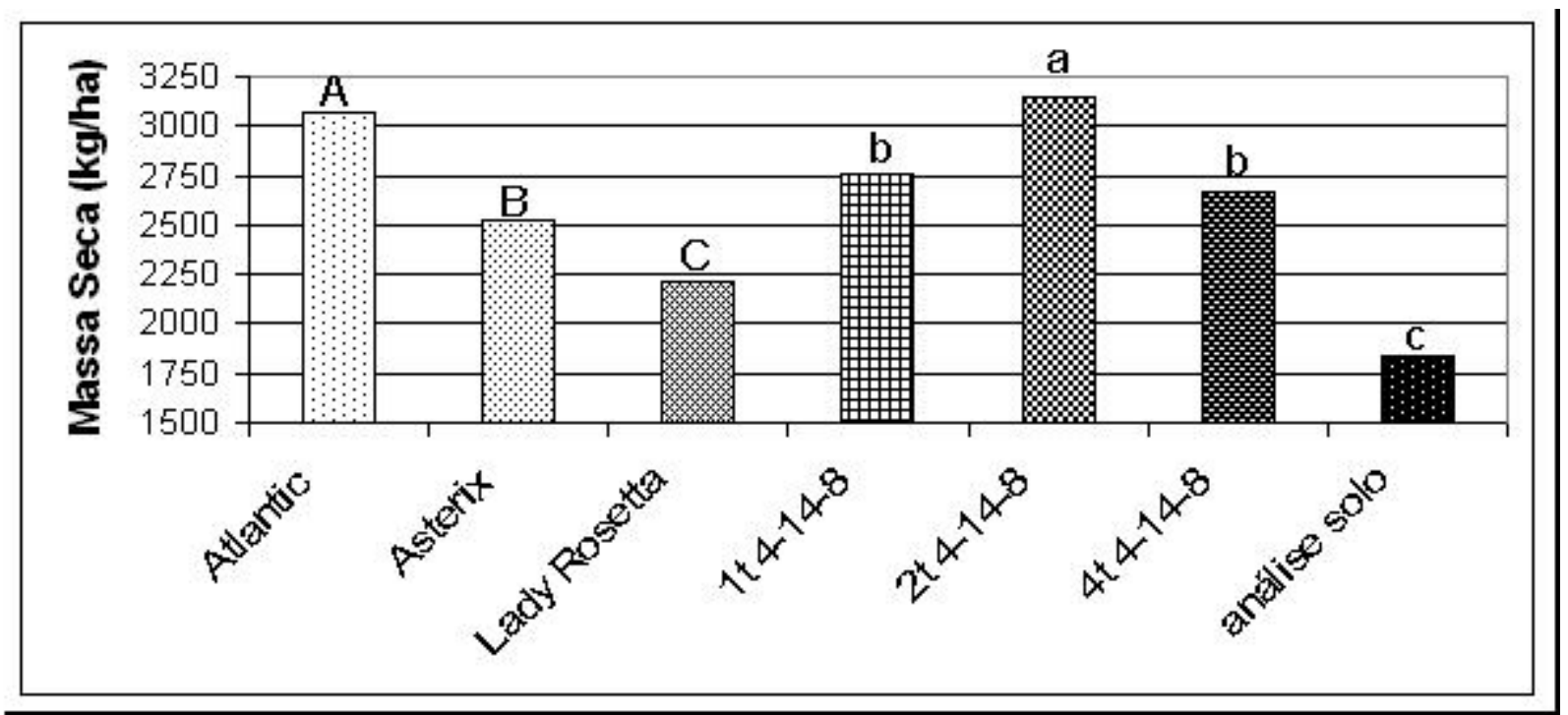

Figura 1. Produção de massa seca de tubérculos de batata sob diferentes adubações em solo de baixa fertilidade. Nova Resende (MG), 2004

Médias de mesma letra, minúsculas comparando adubações e, maiúsculas comparando cultivares, não se diferem entre si, a $5 \%$ de probabilidade pelo Teste de Tukey. 
Entre as adubações testadas, aquela feita com 2 t 4-14-8 ha-1 foi a que propiciou o maior acúmulo de MS nos tubérculos de batata, com $3143 \mathrm{~kg}$ ha-1, seguidas das adubações com 1 e 4 t 4-14-8 ha-1, respectivamen- te, 2759 e 2673 kg de MS ha-1. A adubação de acordo com a análise de solo resultou no menor acúmulo de MS pelas cultivares de batata, em solo de baixa fertilidade, com média de $1832 \mathrm{~kg}$ ha-1 (Tabela 2).

Tabela 2 - Produção de massa seca dos tubérculos (PMST), classe I (PMSI), classe II (PMSII), classe III (PMSIII) e classe IV (PMSIV) de cultivares de batata sob diferentes adubações em solo de baixa fertilidade. Nova Resende (MG), 2004

\begin{tabular}{|c|c|c|c|c|c|}
\hline & "PMST & PMSI & PMSII & PMSIII & PMSIV \\
\hline \multicolumn{3}{|l|}{ Cultivar } & \multicolumn{2}{|c|}{ kg ha-1 } & \\
\hline Atlantic & $3063 \mathrm{~A}$ & $772 \mathrm{~A}$ & $1336 \mathrm{~A}$ & \multirow{2}{*}{$\begin{array}{c}855 \mathrm{AB} \\
1072 \mathrm{~A}\end{array}$} & 135 \\
\hline Asterix & $2527 \quad B$ & $324 \quad B$ & 732 & & $423 \mathrm{~A}$ \\
\hline Lady Rosetta & 2216 & $282 \quad B$ & $963 \quad \mathrm{~B}$ & 710 & $281 \quad B$ \\
\hline \multicolumn{6}{|l|}{ Adubação } \\
\hline $1 \mathrm{t} \mathrm{4-14-8} \mathrm{ha-1}$ & $2759 \quad b$ & 381 bc & $1090 \mathrm{a}$ & $998 \quad a$ & $328 a$ \\
\hline 2 t 4-14-8 ha-1 & $3143 a$ & $639 a$ & $1231 \mathrm{a}$ & $1042 \mathrm{a}$ & $270 a$ \\
\hline 4 t 4-14-8 ha-1 & $2673 \quad b$ & $544 a b$ & $967 a b$ & $937 \quad a$ & $265 a$ \\
\hline \multicolumn{6}{|l|}{$40 \mathrm{~kg} \mathrm{~N}+$} \\
\hline $420 \mathrm{~kg} \mathrm{P} 2 \mathrm{O} 5+$ & 1832 & 275 & 754 & 539 & $255 a$ \\
\hline \multicolumn{6}{|l|}{220 kg K2O ha-1 } \\
\hline
\end{tabular}

Médias seguidas de mesma letra, minúscula comparando adubações e maiúscula comparando cultivares nas colunas, não diferem estatisticamente entre si, a 5\% de probabilidade pelo Teste de Tukey.

$\mathrm{Na}$ avaliação da produtividade do feijoeiro em função do aproveitamento do adubo residual deixado pelas interações cultivares de batata $x$ adubações, em solo de baixa fertilidade, ocorreram diferenças altamente significativas $(P<0,01)$ em relação às adubações residuais empregadas, sem interferência das cultivares de batatas anteriormente utilizadas.

A adubação residual de maior incremento na produtividade do feijoeiro foi aquela que se empregou a adubação de acordo com a análise de solo para a cultu- ra da batata, resultando em 2502 kg ha-1 de grãos, superior as demais adubações da formulação com 4-14-8. A mesma adubação resultou na menor produtividade entre as cultivares de batata (acúmulo de MS) (Figura 2), demonstrando que a adubação de acordo com a análise de solo para a cultura da batata, com altas dosagens de nutrientes e com as fontes utilizadas (sulfato de amônio, superfosfato simples e cloreto de potássio), não reverteram em produtividade na cultura da batata, mas foram reaproveitados pelo feijoeiro.

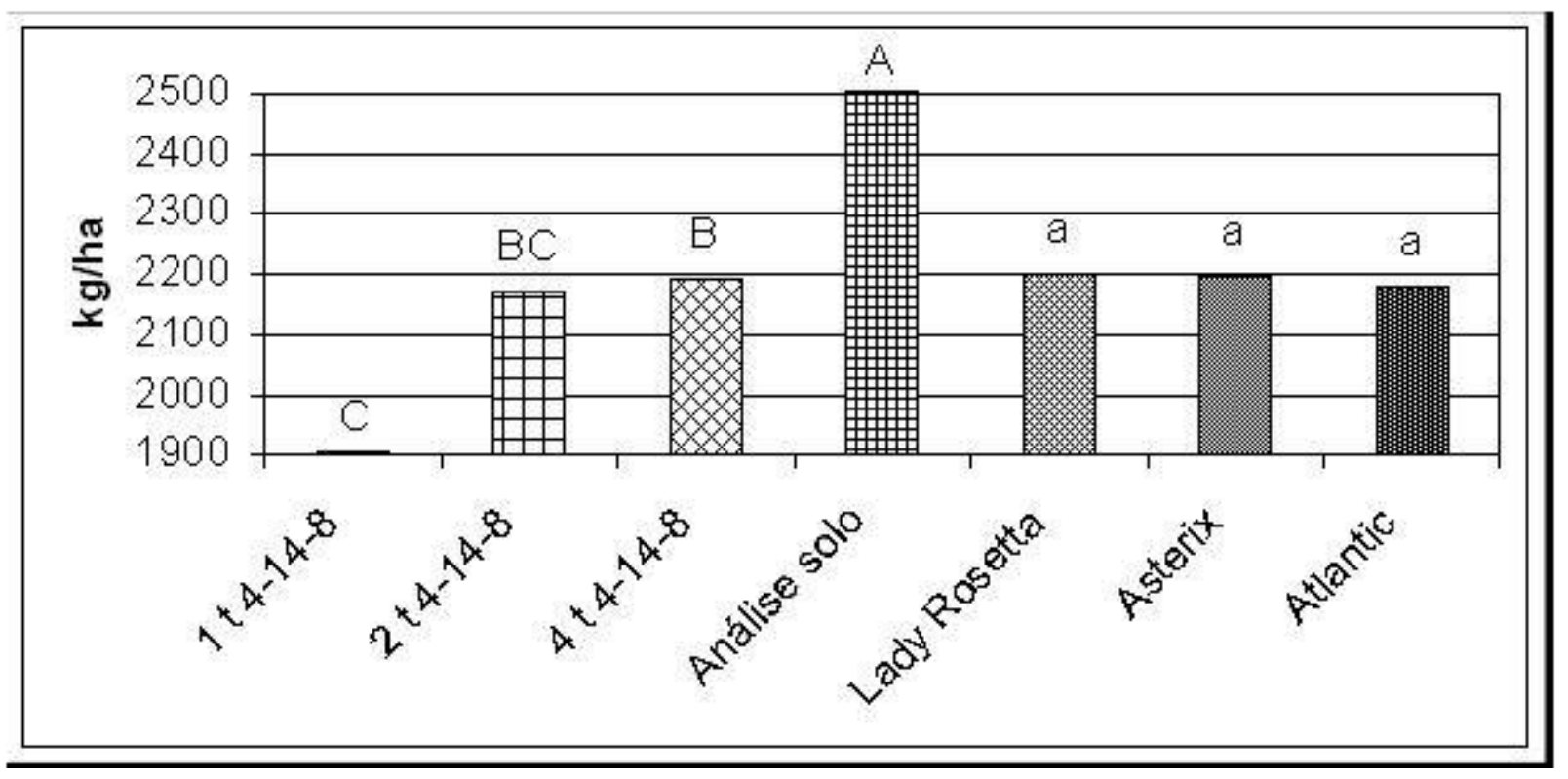


Figura 2. Produtividade do feijoeiro cultivado sob quatro adubações residuais de três cultivares de batata. Nova Resende (MG), 2005

As adubações com 2 e 4 t de 4-14-8 ha-1 resultaram em 2172 e $2191 \mathrm{~kg}$ ha-1 de grãos para o feijoeiro, respectivamente, sem diferença entre si. Mesmas produtividade entre essas duas dosagens de fertilizantes, residuais da batateira, foi observado por Silva et al. (2000) no para a cultura do milho, utilizando as duas quantidades (2 e 4 t) da formulação 4-14-8, sem diferenças significativas na produção de milho.

Com menor produtividade, mas semelhante à adubação com 2 t de 4-14-8 ha-1, a adubação com 1 tonelada do formulado, resultou na produção de 1907 $\mathrm{kg}$ ha-1 de feijão. A produção de MS dos tubérculos das cultivares de batata para as adubações com 1, 2 e 4 t de 4-14-8 ha-1 foram, respectivamente, 2759, 3143 e 2673 $\mathrm{kg}$ de MS ha-1, sendo as adubações com 1 e $4 \mathrm{t}$ iguais entre si e inferiores a adubação de $2 \mathrm{t}$ de 4-14-8 ha-1.

As produtividades de feijão obtidas neste experimento foram semelhantes àquelas obtidas por Castro \& Boaretto (2002), em condição de alto grau tecnológico do feijoeiro na época das águas, que apresentaram rendimentos entre 1900 a 2370 kg ha-1. Kikuti et al. (2002) obteve-se produtividades entre 826 e $2210 \mathrm{~kg}$ ha-1 para o feijoeiro, utilizando adubo residual da batateira, na safra das águas, valores similares ao obtido neste experimento. Os mesmos autores observaram que a produtividade, em mesmas condições de solo (adubo residual), foi superior na safra inverno-primavera, com irrigação suplementar, sob adubação 3 t 4-14-8 ha-1.

\section{CONCLUSÕES}

Em solo de textura franco-arenosa de baixa fertilidade, a maior produtividade do feijoeiro foi obtida sob a utilização da adubação residual da batateira baseada na recomendação da análise de solo. Porém, na associação produtividade feijoeiro e produção de batata em MS, a adubação com 2 t 4-14-8 ha-1 mostrou-se eficaz no acúmulo de MS para a cultura da batata, com elevação dos teores de nutrientes foliares e produtividade do feijoeiro em cultivo sucessivo, acima da média.

\section{AGRADECIMENTOS}

A FAPESP pelo apoio financeiro dado ao projeto e a Técnica de Laboratório Elaine Cristina Ferreira do Laboratório de Análise de Solos e Tecido Foliar do IFSULDEMINAS - campus Muzambinho, pelo empenho e dedicação.

\section{REFERÊNCIAS BIBLIOGRÁFICAS}

BATUGAL, P.A.; CRUZ, A. de la; LIBUNAO, W.H.; KHWAJA, A.M. Intercropping potato with maize in Lowland Philippines. Field Crop Research, Amsterdan, v.25, n.12, p.83-97, 1990.

BREGAGNOLI, M. Qualidade e produtividade de cultivares de batata para indústria sob diferentes adu- bações. 2006. 141 p. Tese (Doutorado em Fitotecnia) - Escola Superior de Agricultura 'Luiz de Queiroz', Piracicaba, 2006.

CAMARGO FILHO, W.P. Produto Interno Bruto (PIB) da cadeia produtiva da batata. Batata Show, Itapetininga, ano1, n.2, p.22, 2001.

CASTRO, A.M.C.; BOARETTO, A.E. Adubação foliar do feijoeiro com nutrientes, vitamina B1 e metionina. Científica, São Paulo, v.a6, p. 173-178, 2002.

FASSBENDER, H.W.; BORNEMIZA, E. Química del suelos, con énfasis en suelos de América latina. Turrialba, IICA, 1987. 420p.

FILGUEIRA, F.A.R. Novo manual de olericultura: agrotecnologia moderna na comercialização de hortaliças. Viçosa:UFV, 2000. 402p.

FONTES, P.C.R. Preparo do solo, nutrição mineral e adubação da batateira. Viçosa, UFV, 1997. 42p.

GOVINDEN, N.; Intercropping of sugar-cane with potato in Mauritius: A successful, cropping system. Field Crop Research, Amsterdan, v.25, n.1-2, p.99-110, 1990.

IMAN, S.A.; HOSSAIN, A.H.M.D.; SIKKA, L.C.; MIDMORE, D.J. Agronomic management of potato/sugarcane intercropping and its economic implications. Field Crop Research, Amsterdan, v.25, p.111-122, 1990.

KIKUTI, H.; ANDRADE, M.J.B.; RAMALHO, M.A.P. Resposta diferencial de cultivares de milho ao efeito residual da adubação da batata. Ciência e Agrotecnologia, Lavras, v.26, n.1, p.108-116, 2002a.

KIKUTI, H.; ANDRADE, M.J.B.; RAMALHO, M.A.P.; ABREU, A.F.B. Viabilidade econômica da adubação adicional de genótipos de feijoeiro em relação ao resíduo da adubação da batata. Pesquisa Agropecuária Brasileira, Brasília, v.37, n.4, p.455-461, 2002b.

MALAVOLTA, E.; VITTI, G.C.; OLIVEIRA, S.A. Avaliação do estado nutricional das plantas: princípios e aplicações. 2 ed. Piracicaba: Potafós, 1997. 319p.

NEVES, E.M.; RODRIGUES, L.; DAYOUB, M.; DRAGONE, P.S. Aplicação de fertilizantes na bataticultura. Comportamento de preços no Plano Real. Batata Show, Itapetininga, ano 3, n.6, p.20-21, 2003.

PERRENOUD, S. Potato: fertilizer for yield and quality. Berne, International Potash Institute, 1993. 94p. (IPIBuletin,8).

RIBEIRO, J.D.R. Associativismo garante futuro do produtor de batatas. Informe Agropecuário, Belo Horizonte, v.20, n.197, p.5-6, 1999. 
SILVA FILHO, A.V. Efeito da adubação da batata (Solanum tuberosum L.) sobre o feijão-de-vagem (Phaseolus vulgaris L.) e milho verde (Zea mays L.). 1985. 120 p. Dissertação (Mestrado em Fitotecnia) - Universidade Federal de Lavras, Lavras, 1985.

SILVA, E.C.; SILVA FILHO, A.V.; ALVARENGA, M.A.R. Efeito residual da adubação da batata sobre a produção do milho-verde em cultivo sucessivo. Pesquisa Agropecuária Brasileira, Brasília, v.35, n.11, p.2151-2155, 2000.

STARK, J.C.; PORTER, G.A. Potato nutrient management in sustainable cropping systems. American Journal of Potato Research, Orono, v. 82, p. 329-338, 2005.

WESTERMANN, D.T. Nutritional requeriments of potatoes. American Journal of Potato Research, Orono, v. 82, p. 301-307, 2005. 